ECOLOGY AND SOCIETY

Home | Archives | About | Login | Submissions | Notify | Contact | Search

ES HOME > VOL. 2, NO. 2 > ART. 13

Copyright $@ 1998$ by The Resilience Alliance-

St. Clair, C. C., M. Bélisle, A. Desrochers, and S. Hannon. 1998. Winter responses of forest birds to habitat corridors and gaps. Conservation Ecology [online] 2(2): 13. Available from the Internet. URL: http://www.consecol.org/vol2/iss2 /art13/

A version of this article in which text, figures, tables, and appendices are separate files may be found by following this link.

\title{
Research
}

\section{Winter Responses of Forest Birds to Habitat Corridors and Gaps}

\author{
$\underline{\text { Colleen Cassady St. Clair }}^{1,2}$, Marc Bélisle $^{2}$, André Desrochers $^{2}$, and Susan Hannon ${ }^{1}$
}

${ }^{1}$ University of Alberta; ${ }^{2}$ Université Laval

- Abstract

- Introduction

- Methods

O Habitat Trials

o Detour Trials

- Results

- Statistical Analyses

○ Habitat Trials

O Detour Trials

- Discussion

- Responses to this Article

- Acknowledgments

- Literature Cited

\begin{abstract}
Forest fragmentation and habitat loss may disrupt the movement or dispersal of forest-dwelling birds. Despite much interest in the severity of these effects and ways of mitigating them, little is known about actual movement patterns in different habitat types. We studied the movement of wintering resident birds, lured by playbacks of mobbing calls, to compare the willingness of forest birds to travel various distances in continuous forest, along narrow corridors (fencerows), and across gaps in forest cover. We also quantified the willingness of Black-capped Chickadees (Poecile atricapillus) to cross gaps when alternative forested detour routes were available. All species were less likely to respond to the calls as distance increased to $200 \mathrm{~m}$, although White-breasted Nuthatches (Sitta carolinensis) and Hairy Woodpeckers (Picoides villosus) were generally less likely to respond than chickadees and Downy Woodpeckers ( $P$. pubescens). Chickadees were as likely to travel in corridors as in continuous forest, but were less likely to cross gaps as the gap distance increased. The other species were less willing to travel in corridors and gaps relative to forest, and the differences among habitats also increased with distance. For chickadees, gap-crossing decisions in the presence of forested detours varied over the range of distances that we tested, and were primarily influenced by detour efficiency (the length of the shortcut relative to the available detour). Over short distances, birds used forested detours, regardless of their efficiency. As absolute distances increased, birds tended to employ larger shortcuts in the open when detour efficiency was low or initial distance in the open was high, but they limited their distance from the nearest forest edge to $25 \mathrm{~m}$. Thus, chickadees were unwilling to cross gaps of $>50 \mathrm{~m}$ when they had forested alternatives, yet they sometimes crossed gaps as large as $200 \mathrm{~m}$ when no such choice existed. Our results suggest that the presence of corridors enhanced the movement of some, but not all, forest birds, and that even chickadees, which were less sensitive to gap width, preferred not to venture far from forest cover.
\end{abstract}

KEY WORDS: Black-capped Chickadee, corridor, detour trials, dispersal, Downy Woodpecker, forest fragmentation, gap width, Hairy Woodpecker, movement, Poecile atricapillus, Picoides pubescens, Picoides villosus, Sitta carolinensis, Whitebreasted Nuthatch.

\section{INTRODUCTION}

Habitat fragmentation is increasing throughout the forested regions of the world and confers a variety of negative effects for forestdwelling birds (see reviews by Wilcove et al. 1986, Saunders et al. 1991, Opdam et al. 1994, Robinson et al. 1995). Beyond the associated and more severe effect of habitat loss (McGarigal and McComb 1995, Fahrig 1997), fragmentation alters population structure 
in remaining habitat patches by impeding the movement of birds among them (Lens and Dhondt 1994, Matthysen et al. 1995, Matthysen and Currie1996). Unfortunately, it has been difficult to quantify the levels and configurations of habitat fragmentation that constrain the movement of individuals, particularly for vagile species like birds. To date, most of the emphasis in the burgeoning literature on habitat fragmentation concerns patterns of occupancy and abundance in habitat patches for which dispersal mechanisms are largely assumed or ignored (Wiens et al. 1993, Ims 1995). The factors that have long been recognized to shape animal movement decisions in behavioral ecology (e.g., learning, predation risk, travel costs) still have no counterpart in the parlance of metapopulations and landscape ecology (see also Wiens et al. 1993, Lima and Zollner 1996).

Because metapopulations are, by definition, connected by the movements of individuals (Gilpin and Hanski 1991, Opdam 1991), a detailed knowledge of the movement of organisms between habitat patches (i.e., through the matrix) is essential for predicting the population effects of fragmentation. The extent to which a matrix impedes movement will depend largely on its spatial configuration (Taylor et al. 1993, Fahrig and Merriam 1994, Ims1995) which, in turn, is perceived by animals at different and highly specific spatial scales (Kotliar and Wiens1990, Keitt et al. 1997). At a coarse scale, a given animal may circumvent an inhospitable matrix only with the help of physical connections or corridors among patches. Such corridors have been shown indirectly to increase movement by diverse species among habitat patches (e.g., Wegner and Merriam 1979, Dunning et al. 1995, Haas 1995, Machtans et al. 1996), although much debate surrounds their utility (see reviews by Simberloff and Cox 1987, Saunders and Hobbs 1991, Hobbs1992, Simberloff et al. 1992, Beier and Noss 1998). At a finer scale, individuals may still perceive sufficient connectivity in the matrix to permit movement among patches (Wiens 1994, 1995, Ims 1995), which may also be described as perceptual range (Lima and Zollner 1996, Zollner and Lima 1997) or gap-crossing abilities (Desrochers and Hannon 1997). Whether or not an animal will cross gaps between patches can be expected to vary among species, patch habitat types, matrix types, and a host of factors not normally associated with landscape ecology, such as weather variables, season, the presence of alternative routes, and associated costs (e.g., perceived predation risk, detour length).

Quantifying the movements of forest species in corridors and gaps has been difficult partly because investigators frequently can neither identify nor provide the motivation for animals to move between patches. Taped playbacks of bird songs or calls offer particular promise for providing this motivation in avian studies. For example, species-specific territorial songs have been used to quantify the willingness of forest birds to enter different matrix types (Sieving et al. 1996) and to cross gaps of open area up to $100 \mathrm{~m}$ adjacent to their territories (Rail et al. 1997). Desrochers and Hannon (1997) generalized this method to nonterritorial situations by using recordings of the mobbing calls of Black-capped Chickadees (Poecile atricapillus) to study the postbreeding dispersal of several forest species. By inducing birds to either cross or take detours around gaps in forest cover, they found that most species showed resistance to gaps as narrow as $50 \mathrm{~m}$, and that birds generally preferred woodland routes even when these detours were three times as long as their gap alternatives. Although all three studies imply that habitat gaps pose problems for forest birds that might be alleviated by corridors, a direct comparison of corridor to matrix use is still needed (Nicholls and Margules1991, Inglis and Underwood 1992, Simberloff et al. 1992). Better resolution of the factors that determine whether or not birds will cross gaps is also needed. Such factors may include the configuration of habitat edges, spatial scale, and the influence of other individuals.

Here, we combine two data sets that address these needs by describing the movements of wintering resident birds responding to playbacks in three habitat types: continuous forest, gaps, and corridors. Both studies assumed that forest birds associate open areas with a higher risk of predation, and both studies focused on resident species in winter for three reasons: resident species may be more sensitive to the effects of habitat fragmentation (Bierregaard et al. 1992, Wiens 1994); winter may constrain behavior when environmental and food stresses are presumably greatest (Ekman 1984, Desrochers et al. 1988, McNamara and Houston 1990); and the effects of winter site fidelity may further limit resident movement. We address the following questions: (1) How does the willingness of birds responding to mobbing calls differ when the intervening habitat is continuous forest, corridors of forest, or gaps between forested patches? (2) How do these responses differ among species? (3) What factors influence the size of gaps that birds will cross when they have the option of traveling exclusively under forest cover?

\section{METHODS}

We studied the movement patterns of forest birds between 10 January and 9 March of 1996 and 1997 in two agricultural-dominated landscapes, one at the southern edge of the boreal forest in north-central Alberta $\left(54^{\circ} 37^{\prime} \mathrm{N}, 113^{\circ} 20^{\prime} \mathrm{W}\right)$ and one in the mixed-wood remnants of the St. Lawrence lowlands near Québec City ( $46^{\circ} 45^{\prime} \mathrm{N}, 71^{\circ} 20^{\prime} \mathrm{W}$ ). Both were comprised of approximately $20^{\circ}$ forest cover with the remainder devoted to crops, grazing, and housing. In Alberta, these forests are dominated primarily by poplar (Populus tremuloides and $P$. balsamifera) and white spruce (Picea glauca); in Québec, by sugar maple (Acer saccharum), yellow birch (Betula alleghaniensis), beech (Fagus grandifolia), and balsam fir (Abies balsamea).

At both locations, we used playbacks of the mobbing calls of Black-capped Chickadees and Red-breasted Nuthatches (Sitta canadensis) to attract winter forest birds to a target destination. Chickadee mobbing calls appear to be highly effective for attracting diverse species in several forest types and seasons (Hurd 1996, Desrochers and Hannon 1997). To allow comparisons among studies, we used the same recording and followed the same broadcasting methods as in Desrochers and Hannon (1997). The calls were broadcasted from a single 5-W speaker connected to a portable tape player, and could be heard by human listeners from approximately $225 \mathrm{~m}$. Responses to the playbacks were considered to occur when birds flew within 10 horizontal meters of the broadcasting speaker. We conducted no trials during gusting or moderate to heavy winds, when temperatures were below $-30^{\circ} \mathrm{C}$, or during moderate to heavy precipitation.

\section{Habitat trials}

In Alberta, we conducted habitat trials in which we compared the willingness of birds to travel in three habitat types: continuous forest; corridors of aspen-dominated forest $<10 \mathrm{~m}$ wide (fencerows); and gaps in forest cover between patches (Fig. 1). For a more detailed description of the study area, see Hannon and Cotterill (1998). During each trial, we played the mobbing calls at a designated origin for a maximum of 6 min or until at least two birds had arrived and no new birds had arrived for 1 min. The purpose of the origin tape was to give a known starting point for the trial. When the origin tape was stopped, a second observer began a tape at the destination and played it for $6 \mathrm{~min}$ or until all of the origin birds had responded. Both observers watched the path of the birds to determine the number and species of birds responding to the destination tape. We scored trials as positive for a given species when one or more individuals from the origin responded (responses were typically the same within chickadee flocks and nuthatch or woodpecker pairs). Responses were scored as negative for a species when no individual detected at the origin also appeared at the destination. For each trial, we also 
recorded the time, temperature $\left( \pm 5^{\circ} \mathrm{C}\right.$ ), and relative measures (on two- or three-point scales) of cloud cover (overcast, partial cloud, sunny), wind speed (no wind, light breeze, steady breeze), and precipitation (none, light rain or snow). The distances between origins and destinations were measured on 1:20 000 aerial maps (gaps) or by pre-calibrated pacing with an accuracy of $5 \mathrm{~m}$. Trials were divided randomly among the three habitat types and approximately evenly among $20-\mathrm{m}$ distance categories ranging from $20 \mathrm{~m}$ to 200 $\mathrm{m}$. Trials were conducted between 0900 and 1600 . Identical sites with a positive response at the origin were not reused and all trials were separated by at least $400 \mathrm{~m}$ spatially or 2 weeks temporally to avoid habituation effects. Origin sites for corridors and both origin and destination sites for gaps consisted of forest patches that were at least 0.5 ha in size.

Fig. 1. Schematic representation of a habitat trial indicating the location of origin (circle) and destination (triangle) speakers in three habitat types. Trial distances ranged from $25 \mathrm{~m}$ to $200 \mathrm{~m}$.

\section{Forest}

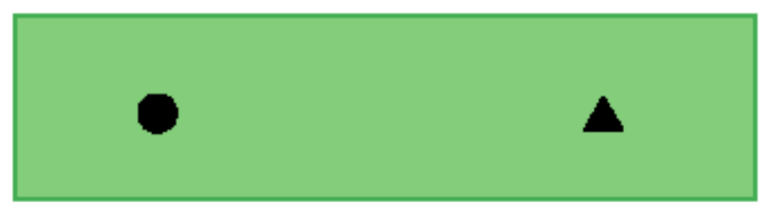

\section{Corridor}
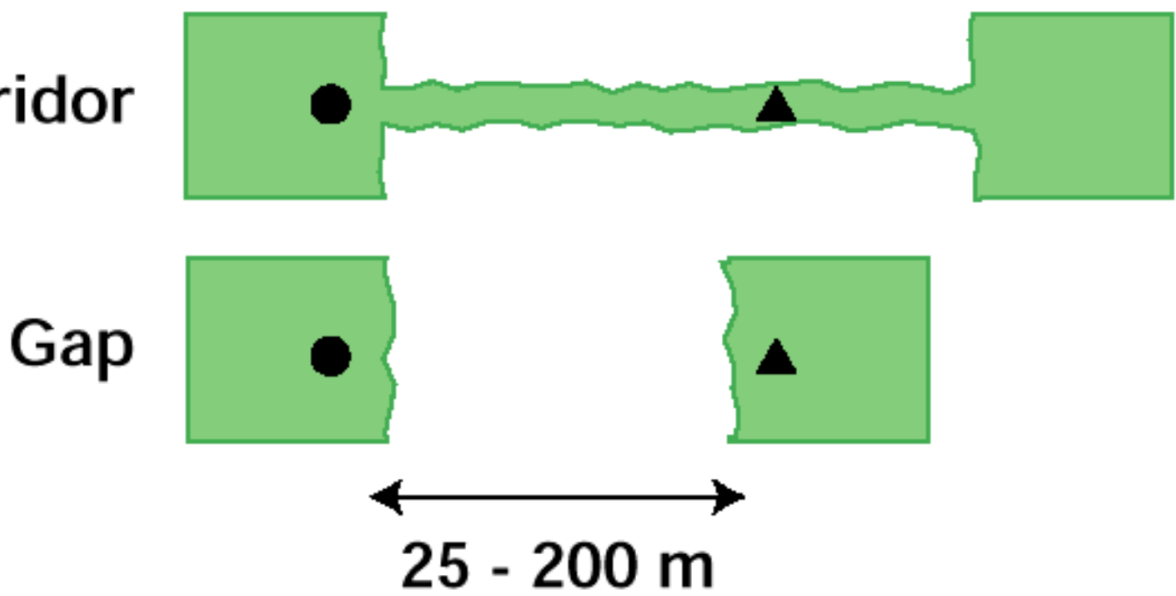

\section{Detour trials}

We conducted detour trials in Québec that were designed to provide a finer resolution of the decision rules made by birds presented with gaps in forest cover. Here, we focused on Black-capped Chickadees and used forest edge configurations in which birds had to choose between a direct route to the destination via a gap (i.e., shortcut), or a longer route under forest cover (Fig. 2; see also Desrochers and Hannon 1997). Mobbing calls were played at the destination site only for 10 min while two observers watched for birds appearing within $10 \mathrm{~m}$ of the forest edge. We did not attract birds to predetermined origins, as they could easily be seen as they arrived at the forest edge. During the playback, the path of as many birds as possible was then followed visually until they reached the destination or the trial ended. Using visual landmarks and a laser range finder (accuracy $1 \mathrm{~m}$ ), we subsequently mapped these paths for each responding individual. To limit interference in crossing decisions, observers were at least $30 \mathrm{~m}$ from both the origin edge and the destination throughout the trial. Distances between the destination site and the nearest origin forest edge were chosen opportunistically, but approximately regularly, between 10 and $200 \mathrm{~m}$. By varying these distances, we created variation in the initial distances available in the open, and corresponding variation in detour length (Fig. 2). Trials were conducted between 0800 and 1600. Trial sites were used only once and were separated by at least $500 \mathrm{~m}$.

Fig. 2. Schematic representation of a detour trial indicating a typical forest edge configuration. The triangle indicates the location of the speaker and circles indicate the locations of focal birds (\#1 and 2) at first sight. For each focal bird, we recorded the initial shortest distance that the bird would have to travel in the open to reach the speaker $\left(\mathrm{DO}_{\mathrm{i}}\right)$, the distance of the route available under forest cover, and the number of conspecifics present. Actual paths taken by birds were recorded as the sum of segments in the open $\left(\mathrm{DO}_{\mathrm{a}}\right)$ and under forest cover $\left(\mathrm{DF}_{\mathrm{a}}\right)$. Note that trials were conducted in both u-shaped (e.g., Bird \#1) and $v$-shaped (Bird \#2) situations. Dependent variables included the proportion of the actual path that occurred in the open (Epsilon $\mathrm{DO}_{\mathrm{a}} /\left(\right.$ Epsilon $\left.\mathrm{DO}_{\mathrm{a}}+\mathrm{Epsilon}_{\mathrm{DF}} \mathrm{a}\right)$ ), the risk area defined between the bird's path and adjacent forest, and the forest edge distances (FED) describing the maximum distances from forest edges that a chickadee ventured during a given shortcut. 


\section{Initial situation}

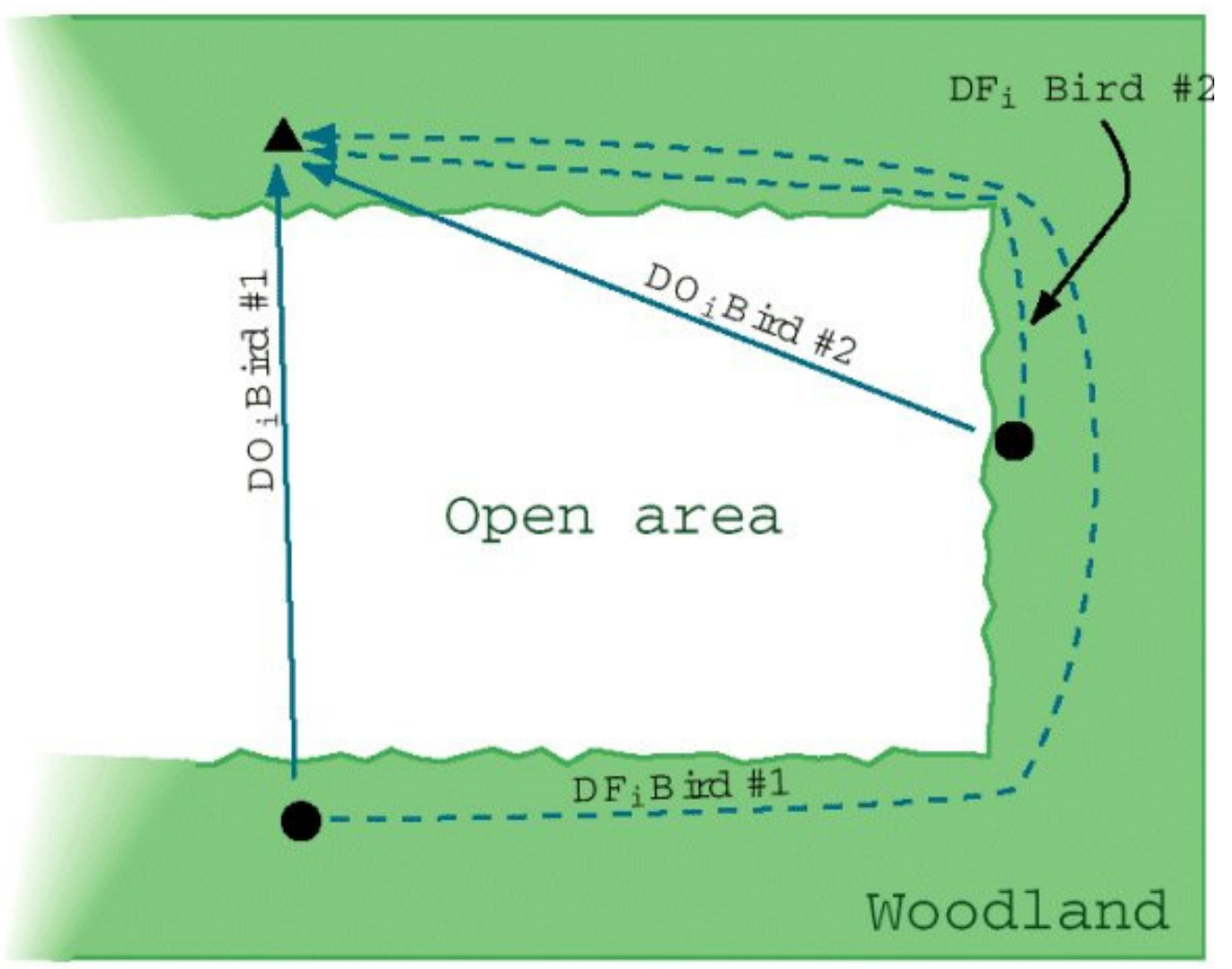

Response by bird

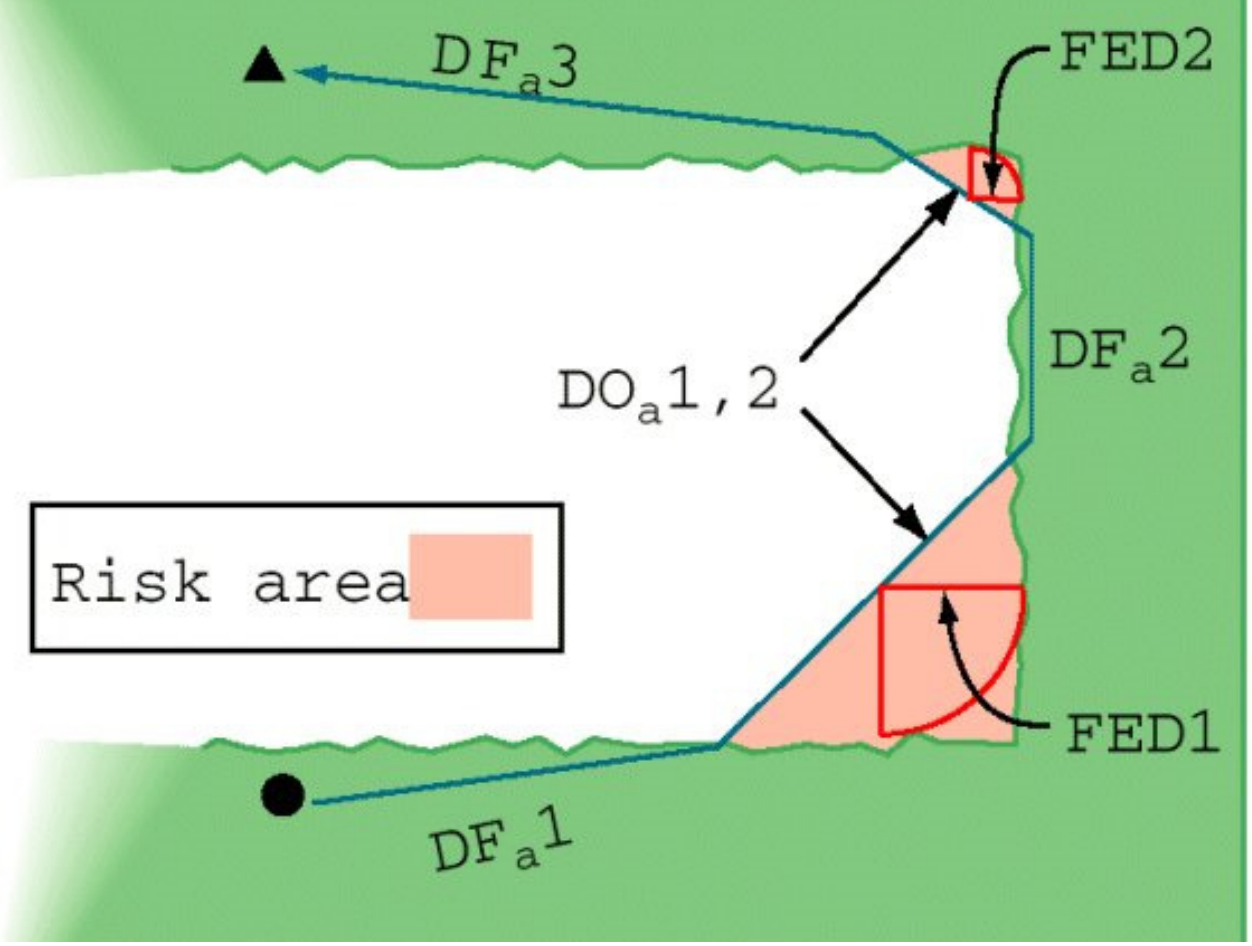


Variation in forest edge configuration (Fig. 2) generated three independent variables that were used in subsequent analyses: the initial distance in the open between a bird's detection point on the origin edge and the destination $\left(\mathrm{DO}_{\mathrm{i}}\right.$, a scale factor); the ratio between the initial distance in the open and the length of the detour route available through the adjacent forest $\left(\mathrm{DO}_{\mathrm{i}} / \mathrm{DF}_{\mathrm{i}}\right.$, the detour ratio); and the interaction between these two terms $\left(D_{i} \times D_{i} / D F_{i}\right)$. For simplicity, we consider the detour ratio $\left(D O_{i} / D F_{i}\right)$ to be an index of detour efficiency. Low values for detour ratios therefore correspond to long detour lengths relative to initial distances in the open (efficient shortcut), whereas high values indicate that both routes are similar in length (inefficient shortcut). Finally, we recorded conspecific group size (the number of individuals observed during the trial) as an additional independent variable. We used three continuous dependent variables as plausible measures of the trade-off birds made between a costly (in terms of time and energy), but safer, route in the forest compared to a shortcut in the open for which lower travel costs may be attended by a greater risk of predation. (1) The proportion of the path length that the bird made in the open indicates the relative use of one or more shortcuts. (2) The size of the risk area formed by the divergence of the bird's path from the adjacent forest integrates two important measures, the length of the path in the open and the distance from that path to the forest edge. (3) The maximum distance that the bird ventured from forest edges (forest edge distance) measures its perceived distance to safety.

\section{Statistical analyses}

We used stepwise logistic regression with backward elimination to measure the effects of independent variables in the habitat trials. The entry and removal thresholds of variables into these models were set at alpha $=0.05$ and alpha $=0.10$, respectively. We used Wald statistics with reference categories to test the significance of multiple comparisons among the categorical variables of habitat type and species, and report $R$ values, which are analogous to partial regression coefficients in linear regression, to describe the direction and strength of these relationships (Norusis 1994). Because we expected that the probability of response would decrease with distance, and would be greater for corridors relative to gaps and for forests relative to corridors in the habitat trials, we report one-tailed probabilities for these variables. For the continuous dependent variables of the detour trials, we used multiple linear regression with variable transformation when variances were heterogeneous. Some independent variables were centered on their means to reduce collinearity (Kleinbaum et al. 1988). Confounding scale effects in detour trials that might originate from the correlation between the DO ${ }_{i}$ $/ \mathrm{DF}_{\mathrm{i}}$ ratio and $\mathrm{DO}_{\mathrm{i}}\left(r_{\mathrm{S}}=0.13, P=0.09, n=158\right)$ were removed as the regression evaluated the contribution of each independent variable after controlling for the contribution of the other independent variables (Type III sums of squares).

The potential effects of conspecific attraction, which would limit the independence of movement decisions among group members (Smith and Peacock 1990, Reed and Dobson 1993, Romey 1996), were addressed in two ways. In the habitat trials, each species was considered to have responded positively if one or more individuals appeared at the destination, generating a single response per conspecific flock. This undoubtedly overestimated positive responses, but avoided confounding habitat type with ease of individual detection, which was more difficult in forest trials. In the detour trials, the paths of individual birds were recorded separately and were given a statistical weight equal to the inverse of the number of paths recorded during the same trial (i.e., each trial was given one degree of freedom and the bird paths making up that trial were analyzed with some fraction of one degree of freedom).

\section{RESULTS}

\section{Habitat trials}

In the habitat trials, birds were successfully attracted to the origin on 92 occasions involving 408 individuals of 11 species. All but two trials included Black-capped Chickadees, and the majority (61\%) of trials were limited to this species. Only three other species occurred in seven or more trials and are included in subsequent analyses: White-breasted Nuthatch (Sitta carolinensis, $n=10$ ), Downy Woodpecker (Picoides pubescens, $n=8$ ), and Hairy Woodpecker ( $P$. villosus, $n=7)$. We used logistic regression to examine the effect of distance, habitat type, the interaction between distance and habitat type, and species $(n=115)$. The probability of response decreased with increasing distance (chi-square $=8.0, \mathrm{df}=1, P=0.003$ ), and was significantly influenced by both species (chi-square $=$ 16.6, $\mathrm{df}=3, P=0.0009$ ) and the interaction between habitat type and distance (chi-square $=19.5, \mathrm{df}=2, P<0.0001$ ). Further examination of the interaction revealed that as distance increased, birds were less likely to respond in gaps than in forest (Wald $=13.8$, $R=-0.30, \mathrm{df}=1, P=0.0001)$, but responses in corridors and forests were indistinguishable $($ Wald $=0.6, R=0.0, \mathrm{df}=1, P=0.2)$. In comparison to chickadees, nuthatches and Hairy Woodpeckers were less likely to respond to the playbacks (Wald $=12.1, R=-0.27, \mathrm{df}$ $=1, P=0.0005 ;$ Wald $=3.7, R=-0.11, \mathrm{df}=1, P=0.06$, respectively), but Downy Woodpeckers were indistinguishable from chickadees (Wald $=0.5, \mathrm{df}=1, R=0.00, P=0.5$ ). None of the time or weather variables reached the criteria for entry into the model. Because the overall sample was heavily biased by chickadee responses, we tested the effect of distance, habitat type, and the distance $x$ habitat type interaction for the nuthatch and woodpeckers alone $(n=25)$. Again, responses were negatively influenced by distance (chi-square $=4.8, \mathrm{df}=1, P=0.03$ ) and the interaction term (chi-square $=8.4, \mathrm{df}=2, P=0.01$ ). Relative to forests, responses were less likely in gaps (Wald $=4.1, R=-0.25, \mathrm{df}=1, P=0.02$ ) and corridors (Wald $=3.2, R=-0.19, \mathrm{df}=1, P=0.04$ ), but corridors and gaps did not differ (Wald $=0.2, R=0.0, \mathrm{df}=1, P=0.5$ ).

We repeated this analysis with chickadees only $(n=90)$ to derive a predictive model of their responses. Again, the probability of response decreased with distance (chi-square $=6.0, \mathrm{df}=1, P=0.01$ ) and the interaction between distance and habitat type (chi-square $=13.8, \mathrm{df}=2, P=0.001$ ). As for the first model, the distance $\mathrm{x}$ habitat type interaction was strong for forest compared to gaps (Wald $=9.3, R=0.29, \mathrm{df}=1, P=0.002$ ), but not for forest compared to corridors (Wald $=0.02, R=0.0, \mathrm{df}=1, P=0.5$ ). Predicted values generated by this model suggest that chickadees are about four times more likely to travel $200 \mathrm{~m}$ in a forest, and 3.5 times more likely to travel that far in a corridor, than they are to cross a similar-sized gap (Fig. 3).

Fig. 3. Probability that Black-capped Chickadees respond to chickadee mobbing calls from increasing distances in forest, corridor, and gap habitats. Predicted probabilities were calculated by logistic regression $(n=90)$. 


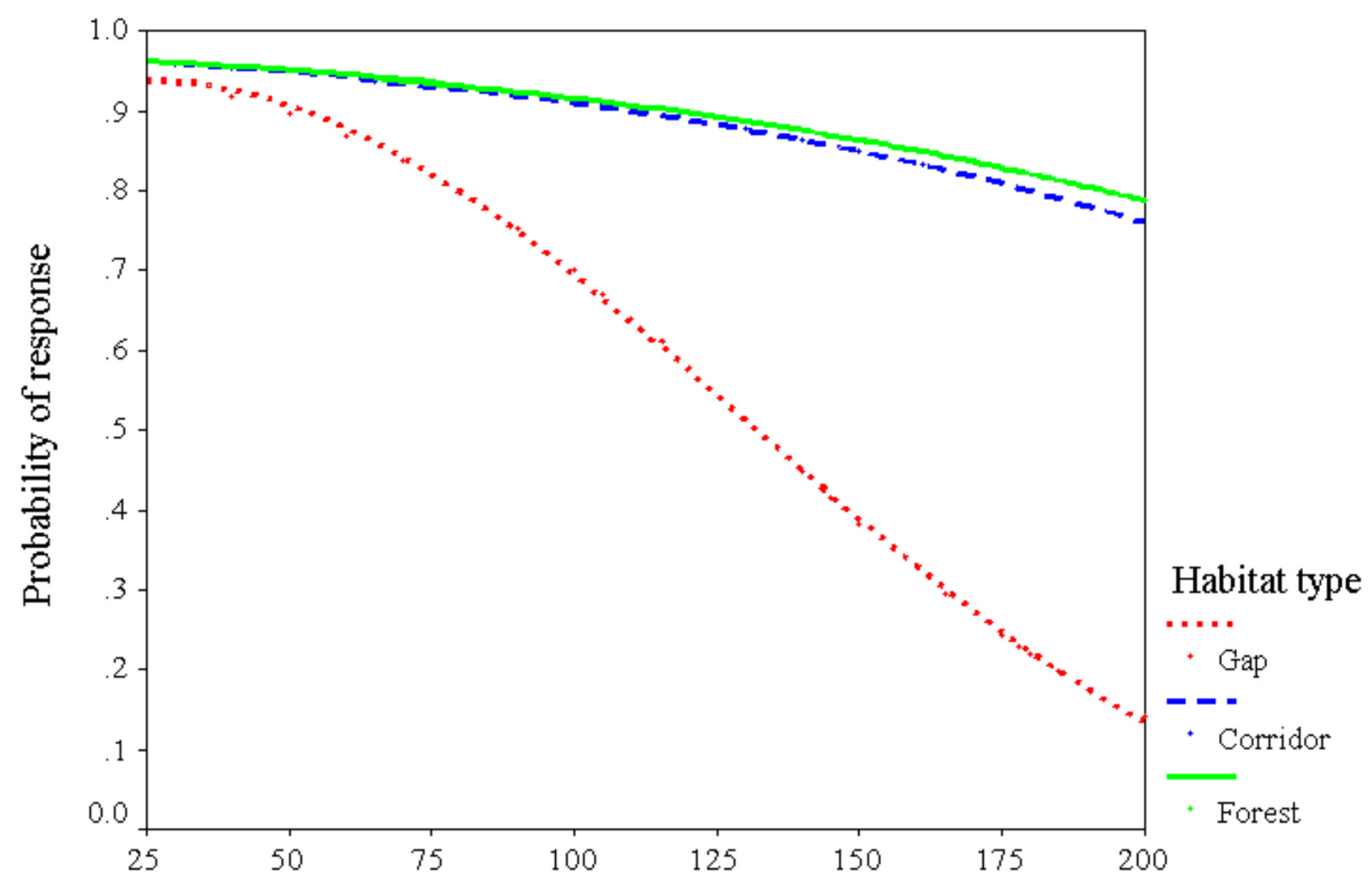

Trial distance (m)

\section{Detour trials}

We conducted 151 trials in which we described 297 paths made by individual chickadees. Forest edge configuration influenced the path choices made by chickadees primarily through the detour ratio $\left(\mathrm{DO}_{\mathrm{i}} / \mathrm{DF}_{\mathrm{i}}\right)$, which accounted for most of the variance in all three continuous response variables (Table 1$)$. The proportion of path length that chickadees actually made in the open [EpsilonDOa / $\left(E_{p s i l o n D O}+E_{a}\right.$ EsilonDFa $)$ increased with $\mathrm{DO}_{i}$ and decreased with increases in the detour ratio (Table 1 ). However, the effect of the detour ratio was not constant, as indicated by a significant negative interaction between the two independent variables $\left(\mathrm{DO}_{\mathrm{i}} / \mathrm{DF}_{\mathrm{i}}\right.$ and $\mathrm{DO}_{\mathrm{i}}$; Table 1). This means that detour efficiency influenced the proportion of path length made in the open at large distances, but had little effect at small distances, when chickadees tended to use the detour regardless of its length. For instance, when the detour ratio exceeded 0.7 and $\mathrm{DO}_{\mathrm{i}}$ was $<115 \mathrm{~m}$, the detour ratio had little predictive value and the proportion of path length that chickadees made in the open was quite variable, ranging from 0 to 1 . By contrast, the detour ratio was very important when the $\mathrm{DO}_{\mathrm{i}} \mathrm{was}>150 \mathrm{~m}$, and the length of shortcuts increased most steeply as the ratio decreased from 0.85 to 0.75 . The size of risk area(s) and forest edge distance(s) gave similar results (Table 1), also indicating that chickadees chose longer shortcuts when the detour ratio declined and the initial distance in the open increased. The negative interaction between the independent variables is perhaps best illustrated with the response variable of forest edge distance; the detour ratio had a larger effect on the distance chickadees ventured from the forest edge as $\mathrm{DO}_{i}$ increased (Fig. 4). Thus, chickadees take the largest shortcuts when they are faced with large initial distances in the open and relatively inefficient alternative routes in the forest.

Fig. 4. The combined effect of the detour ratio $\left(D^{\circ} O_{i} / D F_{i}\right)$ and the initial distance in the open $\left(D_{i}\right)$ on forest edge distance, the distance that chickadees ventured from forest edges. Lower detour ratios represent less efficient detour routes under forest cover. Predicted values were calculated by multiple linear regression $(n=151)$. 


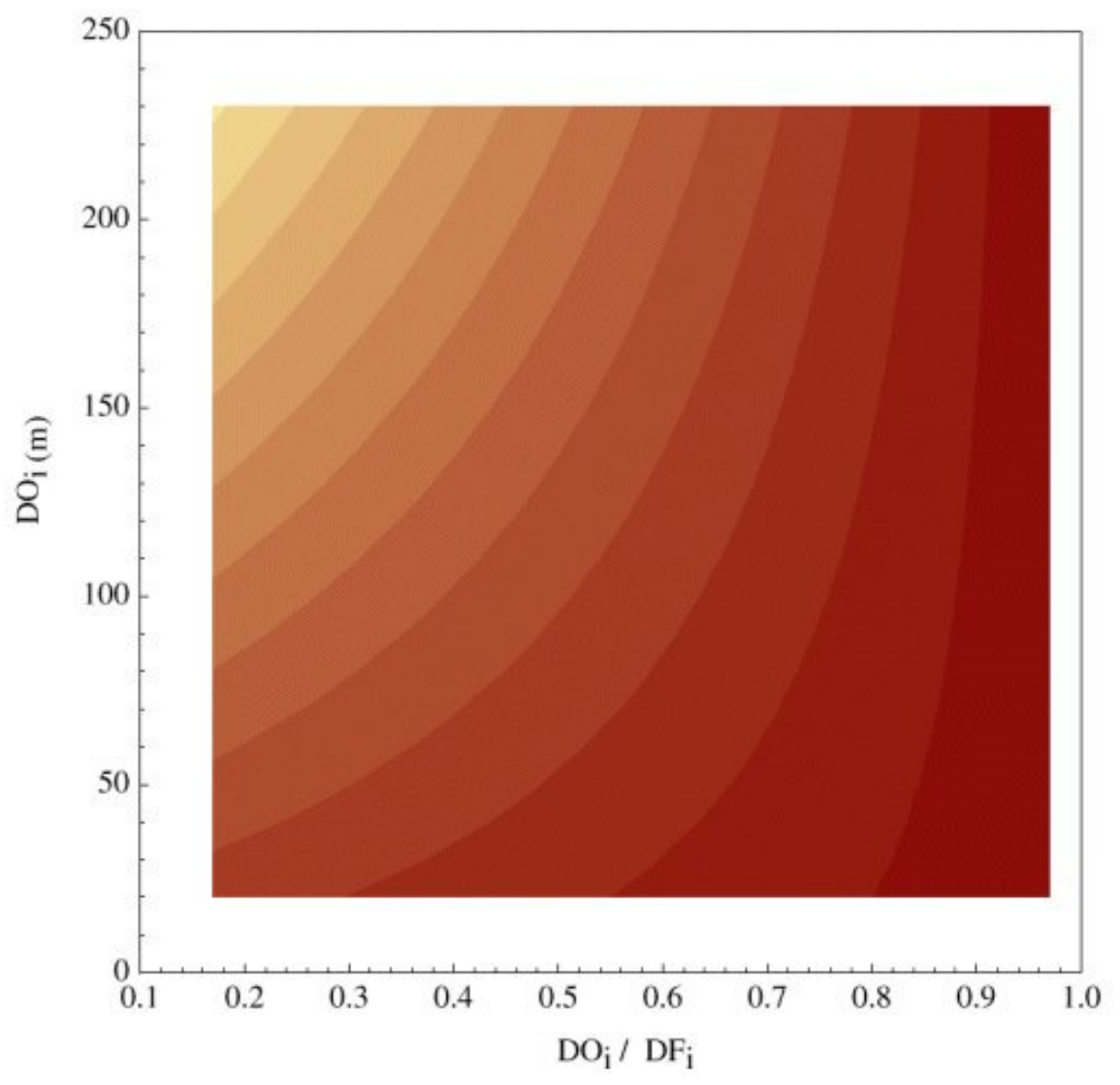

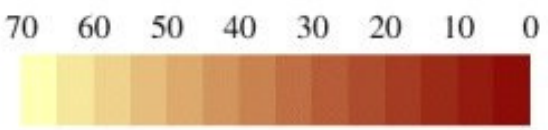

Forest edge distance $(\mathrm{m})$

Table 1. Results of multiple linear regressions (Type III sums of squares) investigating the influence of forest edge configuration and conspecific group size on three response variables describing aspects of the paths made by Black-capped Chickadees in detour trials ( $n=151$; see Fig. 2 for variable definitions).

\begin{tabular}{|c|c|c|c|c|c|c|}
\hline Response variable & $\begin{array}{c}\text { Independent } \\
\text { variable }^{a}\end{array}$ & Beta & $\begin{array}{c}1 \mathrm{SE} \\
\text { (Beta) }\end{array}$ & $\begin{array}{c}\text { Partial } \\
r\end{array}$ & $\begin{array}{c}\text { Partial } \\
F\end{array}$ & $P$ \\
\hline \multirow{5}{*}{$\begin{array}{l}\text { Proportion of path length traveled in the open } \\
(\mathrm{m}) \\
\text { EpsilonDO }_{a} /\left(\text { EpsilonDO }_{a}+\text { EpsilonDF }_{a}\right)^{b}\end{array}$} & $\mathrm{DO}_{\mathrm{i}} / \mathrm{DF}_{\mathrm{i}}$ & -126.4 & 12.5 & -0.64 & 101.8 & $<0.0001$ \\
\hline & $\mathrm{DO}_{\mathrm{i}}(\mathrm{m})$ & 1.04 & 0.21 & 0.39 & 25.3 & $<0.0001$ \\
\hline & $\mathrm{DO}_{\mathrm{i}} \times \mathrm{DO}_{\mathrm{i}} / \mathrm{DF}_{\mathrm{i}}$ & -2.04 & 0.29 & -0.50 & 49.1 & $<0.0001$ \\
\hline & Group size & 0.33 & 0.44 & 0.06 & 0.6 & 0.5 \\
\hline & Constant & 90.1 & 14.8 & - & 37.3 & $<0.0001$ \\
\hline \multirow{5}{*}{$\begin{array}{l}\text { Risk area }\left(\mathrm{m}^{2}\right) \\
\text { (square-root transformed) }\end{array}$} & $\mathrm{DO}_{\mathrm{i}} / \mathrm{DF}_{\mathrm{i}}$ & -68.4 & 6.3 & -0.67 & 116.7 & $<0.0001$ \\
\hline & $\mathrm{DO}_{\mathrm{i}}(\mathrm{m})$ & 0.09 & 0.03 & 0.25 & 9.9 & 0.002 \\
\hline & $\mathrm{DO}_{\mathrm{i}} \times \mathrm{DO}_{\mathrm{i}} / \mathrm{DF}_{\mathrm{i}}$ & -0.14 & 0.16 & -0.07 & 0.8 & 0.4 \\
\hline & Group size & -0.32 & 0.27 & -0.10 & 1.4 & 0.2 \\
\hline & Constant & 22.1 & 2.1 & - & 109.7 & $<0.0001$ \\
\hline \multirow[t]{5}{*}{ Forest edge distance (m) } & $D O_{i} / D F_{i}$ & -35.5 & 4.04 & -0.59 & 77.2 & $<0.0001$ \\
\hline & $\mathrm{DO}_{\mathrm{i}}(\mathrm{m})$ & 0.07 & 0.02 & 0.33 & 17.4 & 0.0001 \\
\hline & $\mathrm{DO}_{\mathrm{i}} \times \mathrm{DO}_{\mathrm{i}} / \mathrm{DF}_{\mathrm{i}}$ & -0.26 & 0.10 & -0.21 & 6.8 & 0.01 \\
\hline & Group size & -0.17 & 0.17 & -0.08 & 1.0 & 0.3 \\
\hline & Constant & 13.3 & 1.3 & - & 98.1 & $<0.0001$ \\
\hline
\end{tabular}

${ }^{a} \mathrm{DO}_{\mathrm{i}}(80.4 \pm 33.3 \mathrm{~m}$, mean $\pm 1 \mathrm{SD})$ and $\mathrm{DO}_{\mathrm{i}} / \mathrm{DF}_{\mathrm{i}}(0.67 \pm 0.17)$ were centered on their means to reduce collinearity. Group size averaged $7.3 \pm 3.3$ individuals and ranged between 1 and 18 individuals.

$\mathrm{b}$ To avoid confounding multiple response variables in the analysis, the response variable was, in fact, Epsilon $\mathrm{DO}_{\mathrm{a}}$ and the model included the total path length (Epsilon $\mathrm{DO}_{\mathrm{a}}+$ Epsilon $\mathrm{DF}_{\mathrm{a}}$ ) as a covariable. Because the effects of the covariable are held constant in the analysis, the model can be interpreted as investigating the influence of the other independent variables on the proportion of path length traveled in 
the open.

The importance of forest edge distance is further illuminated by the emergence of a threshold distance of approximately $25 \mathrm{~m}$, beyond which chickadees would not venture (Fig. 5 A and B; $95 \%$ of the observed paths included forest edge distances less than or equal to 24 $\mathrm{m}$ ). This threshold equates to a 50-m gap size, and was not an artifact of site configuration; the actual forest edge distances were highly variable, but typically smaller than the largest distances that birds would have reached if they had crossed in the open along a path defined by $\mathrm{DO}_{\mathrm{i}}$ (Fig. 6A). The relationship between forest edge distance and risk area further underlines a threshold, as chickadees were willing to define relatively large risk areas in U-shaped sites as long as the forest edge distance did not exceed $25 \mathrm{~m}$ (Fig. $6 \mathrm{~B}$ ). None of the response variables was influenced by conspecific group size (Table 1).

Fig. 5. Maximum distance from forest edges (forest edge distance) that Black-capped Chickadees ventured as a function of $(A)$ the efficiency of the initial forested detour option $\mathrm{DO}_{\mathrm{i}} / \mathrm{DF}_{\mathrm{i}}$, and $(\mathrm{B})$ the length of the initial distance in the open, $\mathrm{DO}_{\mathrm{i}}$. The 314 data points shown originate from 151 independent detour trials. 

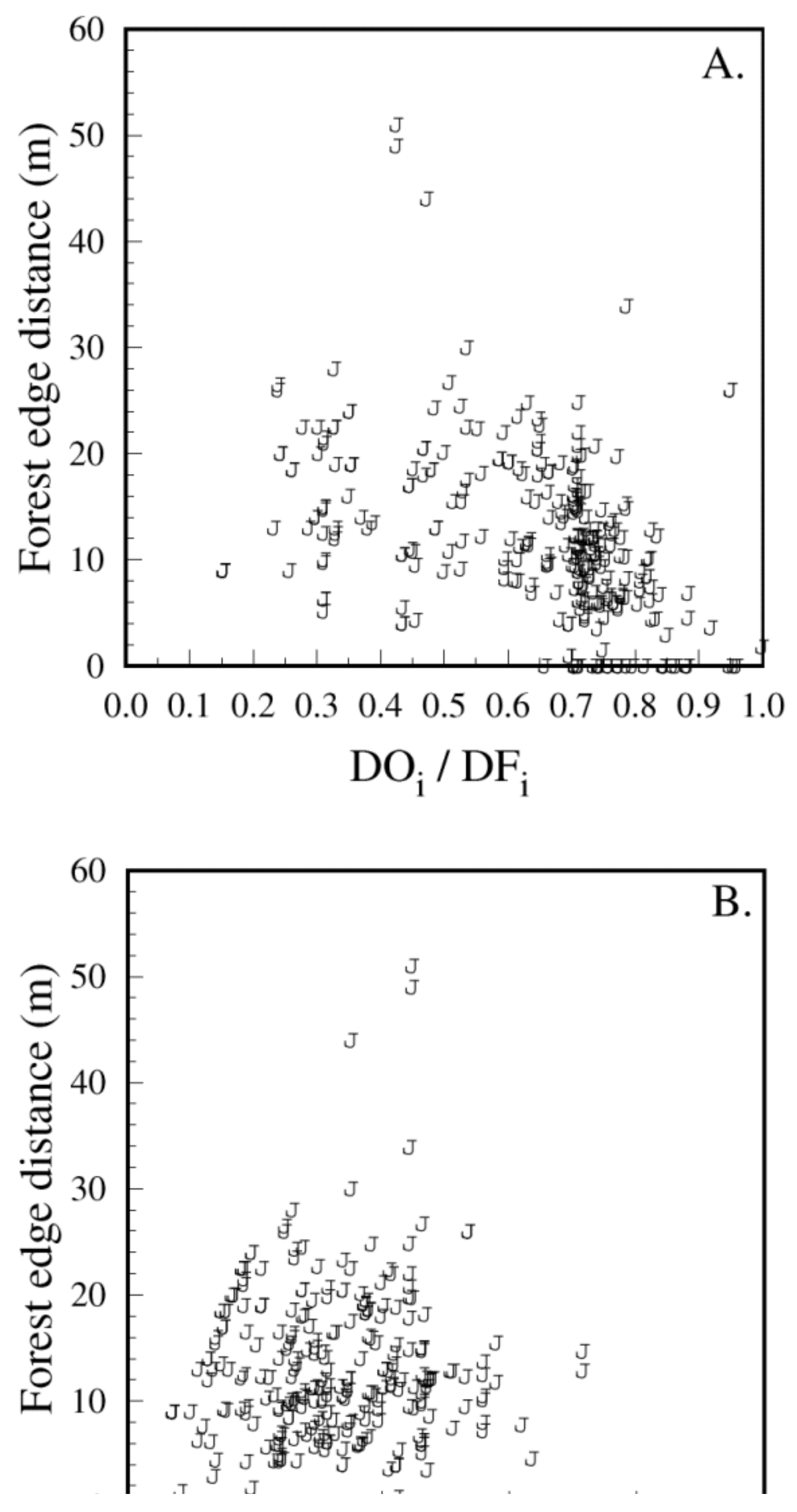
Fig. 6. Forest edge distances exhibited by Black-capped Chickadees taking shortcuts expressed as a function of $(A)$ the hypothetical maximum distance from forest edges that birds would have reached if they crossed in the open along a path defined by the initial distance in the open, $\mathrm{DO}_{\mathrm{i}}$, and (B) the risk area formed by the divergence of the bird's path from the adjacent forest edges. The slope of the relationship in (A) was significantly less than one $\left(H_{0}\right.$ : beta less than or equal to $1, t=-13.3, \mathrm{df}=149, P$ $<0.0001$ ) and $95 \%$ of the actual values were below $24 \mathrm{~m}$ (solid line). The 314 data points shown originate from 151 independent detour trials. 

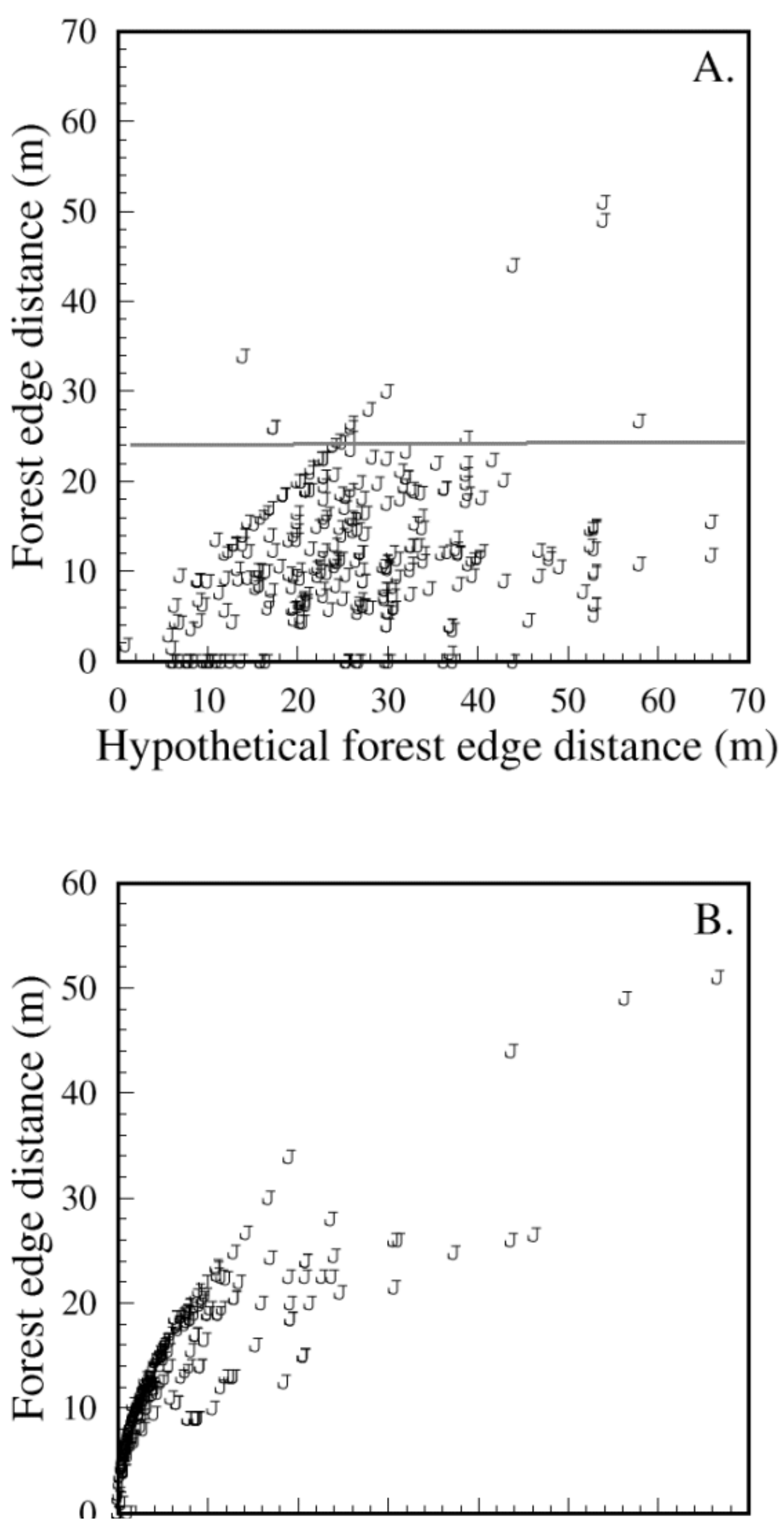


\section{DISCUSSION}

Our results show that corridors as narrow as simple fencerows did facilitate movement for some winter birds, and that these corridors were as effective in promoting short-distance $(<200 \mathrm{~m})$ movement by chickadees as was continuous forest cover. Habitat gaps, in contrast, began to impede movement between patches at relatively short distances; by $100 \mathrm{~m}$, chickadees were $25 \%$ less likely to cross a gap than they were to respond to the mobbing call in a forest or corridor, and this probability was diminished by $>80 \%$ at 200 m (Fig. 3). Chickadees undoubtedly do cross gaps this large and larger (personal observation), but our results quantify their willingness to do so.

Although all species were less willing to cross habitat gaps, responses varied among the four winter residents we studied. Chickadees and Downy Woodpeckers generally exhibited more positive responses than did White-breasted Nuthatches and Hairy Woodpeckers, although all four species share similar life history and habitat characteristics and are often observed traveling together. All responded negatively to gaps, but nuthatches and woodpeckers exhibited a similarly reduced response to corridors relative to forest trials. For these species, corridor width may be critically important (e.g., Tischendorf and Wissel 1997), and fencerows alone might be too narrow to provide adequate cover. Species differences in corridor use may also stem from differing home range sizes or flocking behavior tendencies, both of which tend to be greater for chickadees. Such species differences have important consequences for the way in which these species deal with habitat fragmentation. Our findings strengthen the assertion that results quantifying corridor use cannot easily be generalized across species or habitats (Lynch and Saunders 1991, Lindenmayer 1994). Roland and Taylor (1997) found that, within a guild of parasitoids, the response to habitat fragmentation may occur at different spatial scales depending, in part, on body size. Other spatial, ecological, and behavioral attributes are also likely to influence the reliance of individual species on corridors. We examined these attributes in the context of one species, the Black-capped Chickadee, with the aim of providing a baseline for quantifying and comparing species responses.

Our analyses of chickadee responses to detours suggest that forest edge configuration, an attribute of fragmented landscapes, was important. In all cases, detour efficiency explained the greatest variance in response variables, but our results also suggested that responses were potentially dependent on scale. More specifically, we found that the distance birds traveled in the open generally increased as detours became less efficient (i.e., lower detour ratios), and increased with the initial distance in the open. These results suggest that there are linear components in responsiveness, yet responses were actually highly variable when detours were economical and open distances were $<115 \mathrm{~m}$. Birds clearly respond to detour efficiency and absolute distances in the open, but their sensitivity to both appears to change with the absolute distances involved. Yet, a host of other variables must also influence their decision rules about path choices. Factors such as boldness, dominance, conspecific group size, and internal state have been shown to influence the distance from forest cover at which forest birds will feed, as an index of forager sensitivity to predation risk (e.g., Lima and Dill 1990, Todd and Cowie 1990, Slotow and Paxinos1997). Given these effects and the potential importance of environmental conditions (McNamara and Houston 1990), we were surprised by the consistent absence of conspecific group size and weather effects in our results.

The importance of spatial scale was further underlined by the response variables of risk area and forest edge distance, where the interaction between the initial distance in the open and detour efficiency was again apparent. Both response variables decreased with detour efficiency (i.e., higher detour ratios), but increased with the initial distance in the open. Thus, the maximum distance chickadees ventured from forest edges (forest edge distance) depended on detour efficiency only at large initial distances, and birds typically chose the forest path, regardless of its efficiency at smaller distances. These results suggest that detour options appear to be important determinants of path choices only when a certain gap threshold is reached. The fact that chickadees used detours indiscriminately at short distances suggests that they prefer to travel under forest cover unless their options are economically or spatially constrained.

Perhaps the most interesting result from our analyses of detours was the clear emergence of a threshold distance from forest edges beyond which birds would not venture. This threshold, occurring at about $25 \mathrm{~m}$, was apparent in all treatments of the forest edge distance variable and was not caused by spurious limits in the potential distance from forest edges that birds could venture at the outset of trials. Thus, it appears that chickadees, given the choice of detouring under forest cover, were unwilling to cross gaps of $>50 \mathrm{~m}$ (i.e., the gap size when they were $25 \mathrm{~m}$ from an edge), a value in accordance with the findings of Desrochers and Hannon (1997) from late summer. Similar gap thresholds have been detected for other species (see Andreassen et al. 1996, Zollner and Lima 1997). Comparing our threshold effect of forest edge distance to the much greater variation in risk area provides some information about the way in which chickadees perceive predation risk. Because birds were more affected by the distance to cover than by increases in the area in which predators may occur, they may equate a relatively constant risk of predation to any open area and rely on the proximity of forest alone to mitigate its effect. Avoidance of gaps at small spatial scales further suggests that chickadees attach a categorical risk to open areas.

The perceptual range (Lima and Zollner 1996) that dictates whether an animal is likely to perceive a landscape as continuing on the other side of a gap, or not, is likely to differ seasonally and regionally. In winter, this distance may either be enhanced, when birds are freed from the requirements of defending a territory or feeding young, or it may decrease with the disappearance of ephemeral (e.g., fruiting) food sources that encourage exploration (Lynch and Saunders 1991). Regional variation in the degree of habitat fragmentation might be expected to influence perceptual range through habituation and possibly even evolutionary changes. Black-capped Chickadees without detour options almost never crossed gaps as large as $100 \mathrm{~m}$ in Québec during the late summer (Desrochers and Hannon 1997), but the probability of crossing gaps this large was reduced by only $25 \%$ in Alberta during winter. This difference may stem from a greater willingness to cross gaps in winter, from regional differences affecting fragmentation responses, or from differences in the classification of successful crosses (see Methods) that would tend to overestimate crossing propensity in Alberta.

Our results have a variety of implications for the management of forest birds in fragmented landscapes. First, we found direct evidence that Black-capped Chickadees are as willing to travel in corridors (fencerows) as in continuous forest over relatively short (200 $\mathrm{m}$ ) distances. By contrast, fencerows do not appear to facilitate the movement of nuthatches and woodpeckers, although the importance of corridor width should be investigated before their importance is dismissed for these species. Willingness to cross gaps declined precipitously with increasing gap width for all four species. Clearly, the movement of forest birds in winter is negatively affected by large gaps in forest cover, but this may be ameliorated for some species through the maintenance or creation of habitat corridors. 
Chickadees presented with an option of taking shortcuts in the open when a forested detour was available showed a clear preference to travel under forest cover. When detours were relatively costly and the initial open distance was large, chickadees used shortcuts, but avoided gaps $>50 \mathrm{~m}$. Thus, chickadees were most likely to use shortcuts under intermediate conditions when absolute distances were neither trivial nor in excess of an apparent threshold in the distance from forest cover. Other residents, apparently more sensitive to gaps than are chickadees, would be expected to behave even more conservatively. In regions where many larger gaps already exist (e.g., agricultural fields), the creation of forested stepping stones (sensu Simberloff et al. 1992) might facilitate movement. The usefulness of this technique merits exploration.

\section{RESPONSES TO THIS ARTICLE}

Responses to this article are invited. If accepted for publication, your response will be hyperlinked to the article. To submit a comment, follow this link. To read comments already accepted, follow this link.

\section{Acknowledgments:}

Funding and logistical support were provided by the Alberta Sport, Recreation, Parks and Wildife Foundation, the Biodiversity Grants Program (supported by licensing fees of Alberta Hunters and Fishers), the Canadian Circumpolar Institute and the Office of the Vice-President, University of Alberta, the Meanook Biological Research Station, by postdoctoral fellowships from the Izaack Walton Killam Memorial Fund (University of Alberta) and the Centre de Recherche en Biologie Forestière, Université Laval (C.C. St. Clair), by an NSERC graduate scholarship and a PQSPB Kelly Fund Research Grant (M. Bélisle), and by NSERC operating grants (A.Desrochers and S. Hannon). We are grateful to the many landowners who allowed us access and to M. -A. Beaucher, J.-F. Gobeil, S. Jamieson, M. Hoekstra, C. McCallum, S. Roy, and R. St. Clair for wonderful assistance and good company in the field.

\section{LITERATURE CITED}

Andreassen, H. P., R. A. Ims, and O. K. Steinset. 1996. Discontinuous habitat corridors: effects on male root vole movements. Journal of Applied Ecology 33: 555-560.

Beier, P., and R. F. Noss. 1998. (in press) Do habitat corridors provide connectivity? Conservation Biology $121241-1252$.

Bierregaard, R. O., Jr., T. E. Lovejoy, V. Kapos, A. A. dos Santos, and R. W. Hutchings. 1992. The biological dynamics of tropical rainforest fragments. BioScience 42: 859-866.

Desrochers, A., and S. J. Hannon. 1997. Gap crossing decisions by forest songbirds during the post-fledging period. Conservation Biology 11: 1204-1210.

Desrochers, A., S. J. Hannon, and K. E. Nordin. 1988. Winter survival and territory acquisition in a northern population of Blackcapped Chickadees. Auk 105: 727-736.

Ekman, J. 1984. Density-dependent seasonal mortality and population fluctuations of the temperate zone willow tit (Parus montanus). Journal of Animal Ecology 53: 119-134.

Fahrig, L. 1997. Relative effects of habitat loss and fragmentation on population extinction. Journal of Wildlife Management $\mathbf{6 1}$ : 603-610.

Fahrig, L., and G. Merriam. 1994. Conservation of fragmented populations. Conservation Biology 8: 50-59.

Gilpin, M., and I. Hanski, editors. 1991. Metapopulation dynamics: empirical and theoretical investigations. Academic Press, London, UK.

Haas, C. M. 1995. Dispersal and use of corridors by birds in wooded patches on an agricultural landscape. Conservation Biology 9:845-854.

Hannon, S. J., and S. E. Cotterill. 1998. Nest predation in aspen woodlots in an agricultural area in Alberta: the enemy from within. Auk 115: 16-25.

Hobbs, R. J. 1992. The role of corridors in conservation: solution or bandwagon? Trends in Ecology and Evolution 7: $389-392$.

Hurd, C. R. 1996. Interspecific attraction to the mobbing calls of Black-capped Chickadees (Parus atricapillus). Behavioral Ecology and Sociobiology 38: 287-292.

Ims, R. A. 1995. Movement patterns related to spatial structures. Pages 85-109 in L. Hansson, L. Fahrig, and G. Merriam, editors. Mosaic landscapes and ecological processes. Chapman and Hall, London, UK.

Inglis, G., and A. J. Underwood. 1992. Comments on some designs proposed for experiments on the biological importance of corridors. Conservation Biology 6: 581-586.

Keitt, T. H., D. L. Urban, and B. T. Milne. 1997. Detecting critical scales in fragmented landscapes. Conservation Ecology [online]1: 4. Available from the Internet at URL: http://www.consecol.org/vol1/iss1/art4.

Kleinbaum, D. G., L. L. Kupper, and K. E. Muller. 1988. Applied regression analysis and other multivariable methods. Second edition. Duxbury Press, Belmont, California, USA.

Kotliar, N. B., and J. A. Wiens. 1990. Multiple scales of patchiness and patch structure: a hierarchical framework for the study of heterogeneity. Oikos 59: 253-260. 
Lens, L., and A. A. Dhondt. 1994. Effects of habitat fragmentation on the timing of crested tit Parus cristatus natal dispersal. Ibis 136: $147-152$.

Lima, S. L., and L. M. Dill. 1990. Behavioral decisions made under the risk of predation: a review and prospectus. Canadian Journal of Zoology 68: 619-640.

Lima, S. L., and P. A. Zollner. 1996. Towards a behavioral ecology of ecological landscapes. Trends in Ecology and Evolution 11:131-135.

Lindenmayer, D. B. 1994. Wildlife corridors and the mitigation of logging impacts on fauna in the wood-production forests in Southeastern Australia: a review. Wildlife Research 21: 323-340.

Lynch, J. F., and D. A. Saunders. 1991. Responses of bird species to habitat fragmentation in the wheatbelt of Western Australia: interiors, edges and corridors. Pages143-158 in D. A. Saunders and R. J. Hobbs, editors. Nature conservation 2: the role of corridors. Surrey Beatty, Chipping Norton, New South Wales, Australia.

Machtans, C. S., M.-A.Villard, and S. J. Hannon. 1996. Use of riparian buffer strips as movement corridors by forest birds. Conservation Biology 10: 1366-1379.

Matthysen, E., F. Adreaensen, and A. A. Dhondt. 1995. Dispersal distances of nuthatches, Sitta europaea, in a highly fragmented forest habitat. Oikos 72: 375-381.

Matthysen, E., and D. Currie. 1996. Habitat fragmentation reduces disperser success in juvenile nuthatches Sitta europaea: evidence from patterns of territory establishment. Ecography 19: 67-72.

McGarigal, K., and W. C. McComb. 1995. Relationships between landscape structure and breeding birds in the Oregon coast range. Ecological Monographs 65: 235-260.

McNamara, J. M., and A. I. Houston. 1990. The value of fat reserves and the tradeoff between starvation and predation. Acta Biotheoretica 38: 37-61.

Nicholls, A. O., and C. R. Margules. 1991. The design of studies to demonstrate the biological importance of corridors. Pages $49-61$ in D. A. Saunders and R. J. Hobbs, editors. Nature conservation 2: the role of corridors. Surrey Beatty, Chipping Norton, New South Wales, Australia.

Norusis, M. J. 1994. SPSS Advanced Statistics 6.1. SPSS, Chicago, Illinois, USA.

Opdam, P. 1991. Metapopulation theory and habitat fragmentation: a review of holarctic breeding bird studies. Landscape Ecology 5: 93-106.

Opdam, P., R. Roppen, R. Reijnen, and A. Schotman. 1994. The landscape ecological approach in bird conservation: integrating the metapopulation concept into spatial planning. Ibis 137 (Supplement 1): S139-146.

Rail, J.-F., M. Darveau, A. Desrochers, and J. Huot. 1997. Territorial responses of boreal forest birds to habitat gaps. Condor 99 : 976-980.

Reed, J. M., and A. P. Dobson. 1993. Behavioural constraints and conservation biology: conspecific attraction and recruitment. Trends in Ecology and Evolution 8: 253-256.

Robinson, S. K., F. R. Thompson III, T. M. Donovan, D. R. Whitehead, and J. Faabord. 1995. Regional forest fragmentation and the nesting success of migratory birds. Science 267: 1987-1990.

Roland, J., and P. D. Taylor. 1997. Insect parasitoid species respond to forest structure at different spatial scales. Nature (London) 386(6626): 710-713.

Romey, W. L. 1996. Individual differences make a difference in the trajectories of simulated schools of fish. Ecological Modelling 92 : 65-77.

Saunders, D. A., and R. J. Hobbs, editors. 1991. Nature conservation 2: the role of corridors. Surrey Beatty, Chipping Norton, New South Wales, Australia.

Saunders, D. A., R. J. Hobbs, and C. R. Margules. 1991. Biological consequences of ecosystem fragmentation, a review. Conservation Biology 5: 18-32.

Sieving, K. E., M. F. Willson, and T. L. De Santo. 1996. Habitat barriers to movement of understory birds in fragmented southtemperate rainforest. Auk 113: 944-949.

Simberloff, D., and J. Cox. 1987. Consequences and costs of conservation corridors. Conservation Biology 1: 63-71.

Simberloff, D., J. A. Farr, J. Cox, and D. W. MehIman. 1992. Movement corridors: conservation bargains or poor investments? Conservation Biology 6: 493-504.

Slotow, R., and E. Paxinos. 1997. Intraspecific competition influences food return-predation risk trade-off by White-crowned Sparrows. Condor 99: 642-650.

Smith, A. T., and M. M. Peacock. 1990. Conspecific attraction and the determination of metapopulation colonization rates. Conservation Biology 4: 320-323.

Taylor, P. D., L. Fahrig, K. Henein, and G. Merriam. 1993. Connectivity is a vital element of landscape structure. Oikos 68: 
571-573.

Tischendorf, L., and C. Wissel. 1997. Corridors as conduits for small animals: attainable distances depending on movement pattern, boundary reaction and corridor width. Oikos 79: 603-611.

Todd, I. A., and R. J. Cowie. 1990. Measuring the risk of predation in an energy currency: field experiments with foraging blue tits, Parus caeruleus. Animal Behaviour 40:112-117.

Wegner, J. F., and G. Merriam. 1979. Movements by birds and small mammals between a wood and adjoining farmland habitats. Journal of Applied Ecology 16: 349-357.

Wiens, J. A. 1994. Habitat fragmentation: island v. landscape perspectives on bird conservation. Ibis 137: S97-S104.

. 1995. Landscape mosaics and ecological theory. Pages1-26 in L. Hansson, L. Fahrig, and G. Merriam, editors. Mosaic landscapes and ecological processes. Chapman and Hall, London, UK.

Wiens, J. A., N. C. Stenseth, B. van Horne, and R. A. Ims. 1993. Ecological mechanisms and landscape ecology. Oikos 66:369-380.

Wilcove, D. S., C. H. McLellan, and A. P. Dobson. 1986. Habitat fragmentation in the temperate zone. Pages $237-256$ in M. E. Soulé, editor. Conservation biology: the science of scarcity and diversity. Sinauer, Sunderland, Massachusetts, USA.

Zollner, P. A., and S. L. Lima. 1997. Landscape-level perceptual abilities in white-footed mice: perceptual range and the detection of forested habitat. Oikos 80: 51-60.

\section{Address of Correspondent:}

Colleen Cassady St. Clair

Department of Biological Sciences

University of Alberta

Edmonton, Alberta, Canada T6G 2E9, and

Centre de Recherche en Biologie Forestière

Pavillon Abitibi-Price, Université Laval

Sainte-Foy, Québec, Canada G1K 7P4

Phone: (403) 492-9685

Fax: (403) 492-9234

cstclair@ualberta.ca

*The copyright to this article passed from the Ecological Society of America to the Resilience Alliance on 1 January 2000. 